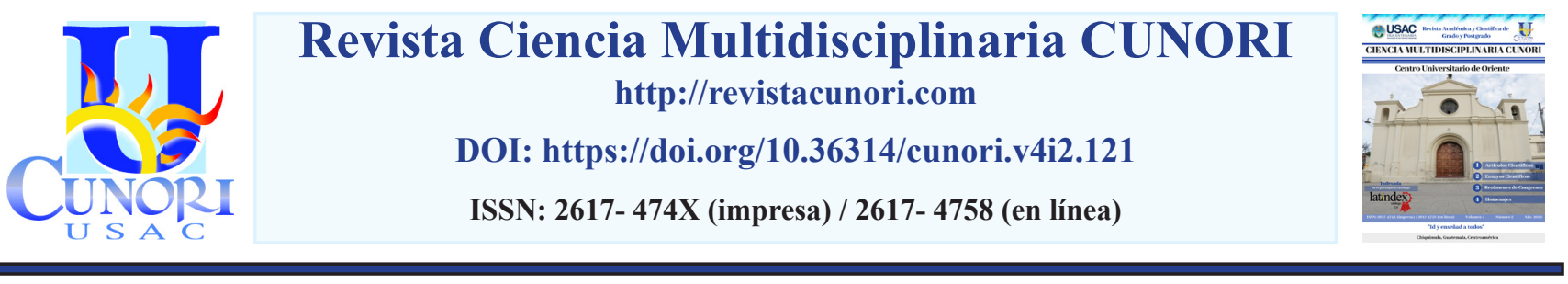

Referencia del artículo

Linares-Portillo, K, L.; Espinoza, A.; Sagastume, L.; Sandoval, K.; Espina M.; y Paz, S. (2020). Cuantificación de anticuerpos de superficie contra hepatitis B con esquema de vacunación incompleto. Revista Ciencia Multidisciplinaria Cunori, 4(2), 1-6. https://doi.org/10.36314/cunori.v4i2.121

\title{
Cuantificación de anticuerpos de superficie contra hepatitis B con esquema de vacunación incompleto
}

\section{Quantification of surface antibodies against hepatitis B in medical with incomplete vaccination}

\begin{abstract}
Karina Lissett Linares Portillo*, Andrea Espinoza, Linda Sagastume, Kevin Sandoval, María Espina y Sofía Paz Centro Universitario de Oriente (CUNORI), Universidad de San Carlos de Guatemala Recibido: 29 de octubre de 2019 / Revisando: 15 de noviembre de 2019 / Aceptado: 20 de mayo de 2020
\end{abstract}

Disponible en internet el 30 de octubre de 2020

*Autor para correspondencia.

Correo electrónico: klisslinares3@yahoo.es

\section{Resumen}

$\mathrm{L}$ a Hepatitis B constituye un problema de salud pública a nivel mundial, la principal forma de prevención es la vacunación, aunque la eficacia de la vacuna está bien establecida, produciendo tasas de inmunización del 95\% o más, la persistencia de inmunidad a largo plazo y con esquemas de vacunación incompletos sigue siendo poco conocida. Esto nos indujo a analizar, la situación de inmunidad frente a la Hepatitis B, en un grupo de doctores y estudiantes de Medicina del Hospital Modular de Chiquimula con un esquema de vacunación incompleto y vacunados hace tres años o más. El tipo de estudio es descriptivo de corte transversal, realizado entre los meses de julio a septiembre de 2019, teniendo una muestra de 23 casos, los instrumentos utilizados para recolectar y registrar información son encuesta y prueba Anti-HBs. A través de este estudio se determinó que de los 23 casos incluidos en el estudio; el 91.30\%(>11 UI/ML) mostraron una respuesta inmunológica efectiva contra hepatitis B, mientras que el 8.7\%(<9 UI/ML) muestra lo contrario y necesitan un refuerzo de la vacuna. De los participantes con 1-2 dosis de vacuna (15 personas), 4 muestran niveles óptimos de Anticuerpos, 10 personas muestran niveles adecuados, mientras que 1 persona obtuvo resultado negativo. Se determinó que $60.87 \%$ de los participantes correspondía al género femenino, de los cuales $56.52 \%$ presentan niveles de anticuerpos adecuados, y $4.35 \%$ obtuvo resultado de anticuerpos negativos ( $<9$ UI/ML). El 39.13\% correspondía al género masculino, de los cuales $34.78 \%$ presentan valores de anticuerpos adecuados, y $4.35 \%$ presenta anticuerpos negativos.

Palabras clave: cuantificación, anticuerpos, hepatitis B, vacunación

Abstract

$\mathrm{H}$ epatitis B is a public health problem worldwide, the main form of prevention is vaccination, although the effectiveness of the vaccine is well established, producing immunization rates of $95 \%$ or more, the persistence of long-term immunity and With incomplete vaccination schedules remains poorly understood. This led us to analyze, the immunity situation against Hepatitis B, in a group of doctors and medical students of the Modular Hospital of Chiquimula with an incomplete vaccination scheme and vaccinated three years or more. The type of study is cross-sectional descriptive, conducted between the months of July to September 2019, having a sample of 23 cases, the instruments used to collect and record information are survey and test Anti-HBs. Through this study it was determined that of the 23 cases included in the study; $91.30 \%$ showed an effective immune response against hepatitis B while $8.7 \%$ show the opposite and need a vaccine booster. Of the participants with 1-2 doses of vaccine (15 people), 4 show optimal levels of Antibodies, 10 people show adequate levels, while 1 person obtained a negative result. It was determined that $60.87 \%$ of the participants corresponded to the female gender, of which $56.52 \%$ had adequate antibody levels, and $4.35 \%$ 
obtained negative antibody results $(<9) .39 .13 \%$ corresponded to the male gender, of which $34.78 \%$ had adequate antibody values, and $4.35 \%$ had negative antibodies.

Keywords: internal armed conflict, ancestral knowledge, knowledge, ancestral practices, repression, genocide, carriers of culture.

\section{Introducción}

La Hepatitis B es una infección vírica del hígado que puede dar lugar tanto a un cuadro agudo como a una enfermedad crónica, afecta aproximadamente 360 millones de personas, con alrededor de un tercio del mundo con valores detectables de anticuerpos contra el VHB. El índice de infección actual en Guatemala es intermedio, de un 2 a 7\%. (García, 2016). Desde 1991, la Organización Mundial de la Salud, recomendó la incorporación de vacunas para VHP en los programas de inmunización. La vacuna contra la hepatitis B contiene una de las proteínas de la envoltura del virus de la hepatitis B, el antígeno de superficie de la Hepatitis B. Después del curso de tres dosis inyectadas, se espera que el sistema inmunitario haya creado anticuerpos contra el HBsAg y se hayan establecido en la circulación sanguínea. El anticuerpo formado se conoce como anti - HbsAg y provee memoria inmunitaria en contra de la hepatitis B. (García, 2017).

Un resultado "positivo" o "reactivo" de la prueba de HBsAb (o anti-HBs) indica que la persona respondió con éxito a la vacuna contra la hepatitis B o se ha recuperado de una infección aguda por hepatitis B. Este resultado (junto con un resultado de HBsAg negativo) significa que es inmune a (está protegido de) una infección futura por hepatitis B. (Hepatitis B Foundation, 2019). Siendo la hepatitis $\mathrm{B}$ una enfermedad prevenible, es de suma importancia conocer el índice de respuesta inmunológica de estudiantes de medicina y médicos del Hospital Modular de Chiquimula, que han recibido esquema de vacunación incompleto contra Hepatitis B o han sido vacunados hace varios años, de igual manera determinar si necesitan la administración de un refuerzo de la vacuna.

\section{Materiales y métodos}

Se realizó un estudio descriptivo transversal, mediante la aplicación de una encuesta a 52 médicos y estudiantes de medicina del Hospital Modular de Chiquimula, de forma probabilística, aleatorio simple, a partir de los resultados obtenidos de la encuesta se seleccionó una muestra de 23 casos que cumplían con los siguientes criterios: médicos y estudiantes con 3 años o más con esquema de vacunación completo contra Hepatitis B, médicos y estudiantes con esquema de vacunación incompleto contra Hepatitis B y no fumadores. Posteriormente se les tomo una muestra sanguínea para su análisis, el cual se hizo por medio de la prueba Anti-HBs.

\section{Resultados}

Se evidencio que de 23 personas incluidas en el estudio, solo el 35\% (8 personas) cuentan con el esquema completo de la vacuna ( 3 dosis). Cabe resaltar que aún en las personas que no cumplieron con el esquema, el grado de inmunización fue alto, ya que aproximadamente el 90\% alcanzo niveles adecuados de anticuerpos contra VHB, siendo mayores de $11 \mathrm{Ul} / \mathrm{ml}$. 
Figura No. 1. Cuantificación de anticuerpos para Hepatitis B en grupo con 1-2 dosis.

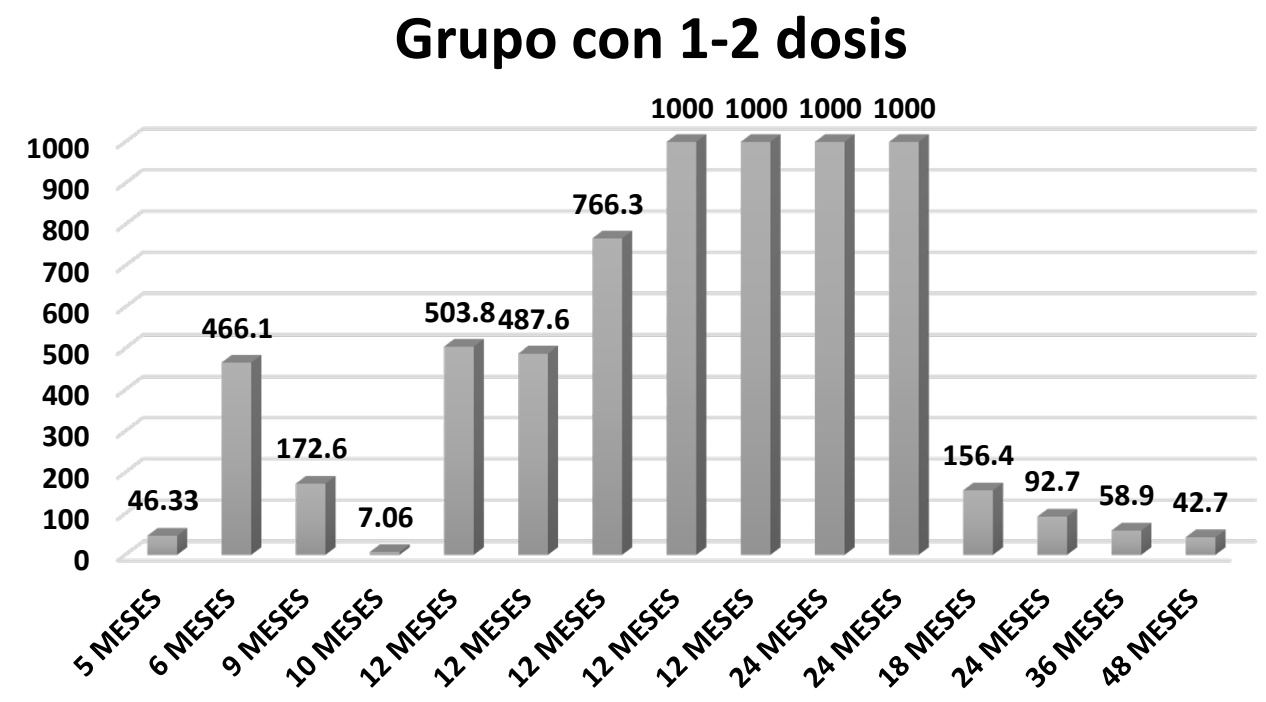

Linares-Portillo (2020). Base de datos del estudio de campo.

Como se observa en la figura, 12 y 24 meses presentan los valores presentan los valores más altos.

Figura No. 2. Cuantificación de anticuerpos para Hepatitis B en grupo con 3 dosis.

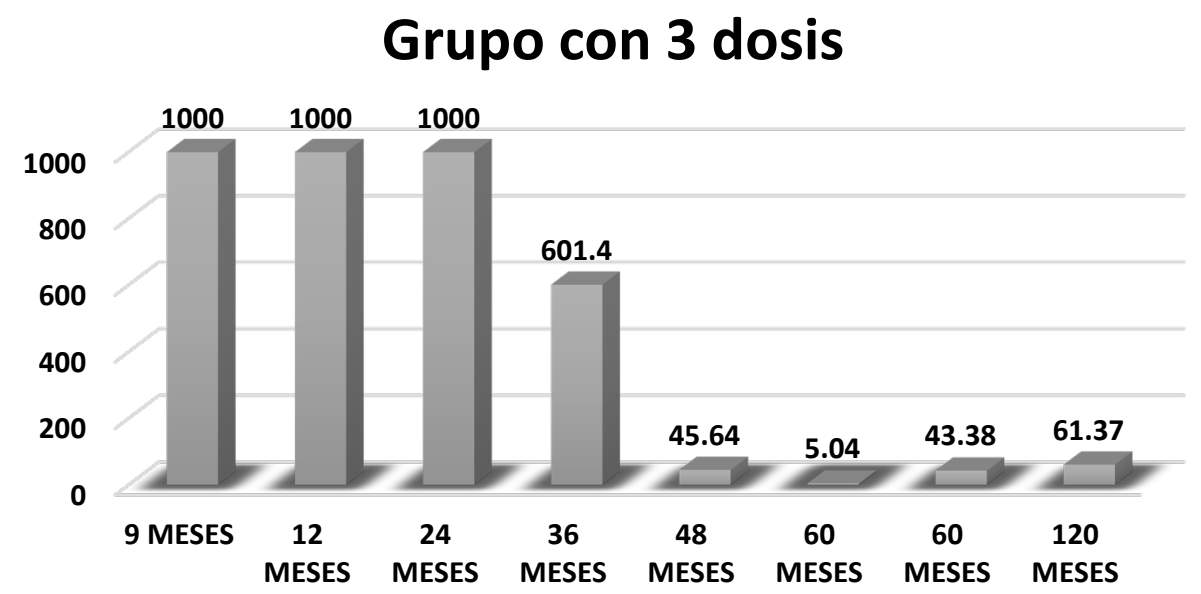

Linares-Portillo (2020). Base de datos del estudio de campo.

En el grupo que cumplió con las 3 dosis de vacuna ( 8 personas), 3 tienen niveles de anticuerpos $>1,000$; 4 personas muestran niveles adecuados de anticuerpos $(>11 \mathrm{UI} / \mathrm{ml})$, y 1 persona obtuvo resultado de anticuerpos negativos, es decir $<9 \mathrm{UI} / \mathrm{ml}$. La vacuna frente a la hepatitis B es muy efectiva en la prevención de la enfermedad. Los estudios poscomercialización han demostrado que un esquema de tres dosis induce concentraciones protectoras de anti-HBs en más del $95 \%$ de los lactantes, niños y adolescentes sanos y en más del 90.\% de los adultos sanos menores de 40 años. Los resultados de nuestro estudio coinciden, ya que de las 8 personas que cumplieron con el esquema para VHB, solamente el 13\% (1 persona) presentó valores negativos de anticuerpos, es decir $<9 \mathrm{mUl} / \mathrm{ml}$. 
Figura 3. Cuantificación de anticuerpos para Hepatitis B según sexo.

Anticuerpos para hepatitis B según sexo

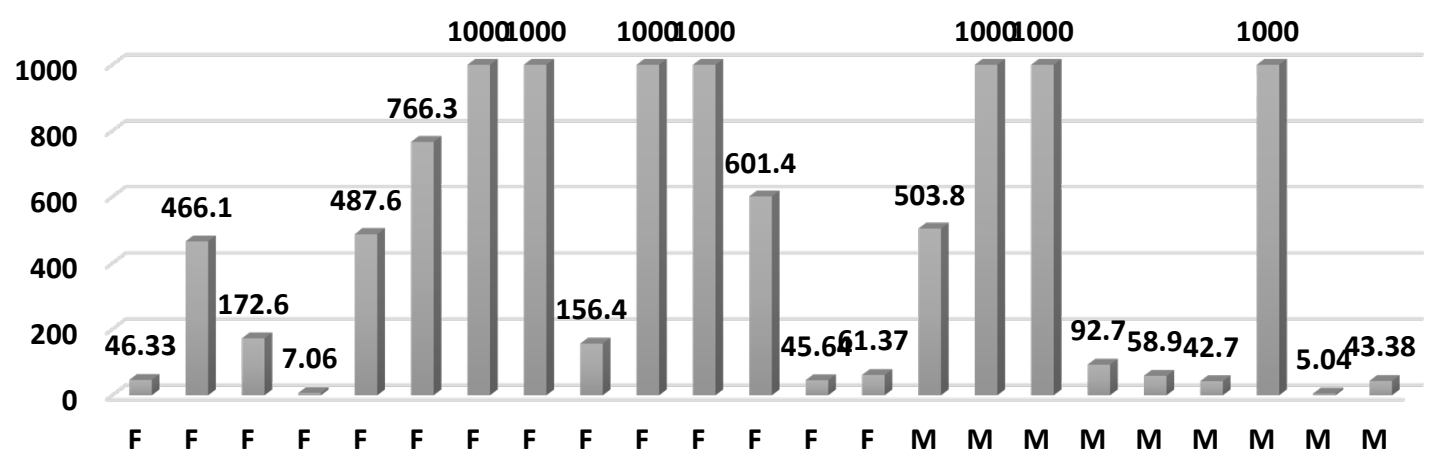

Linares-Portillo (2020). Base de datos del estudio de campo.

Del total de 23 casos incluidos en el estudio, 14 pertenecen al sexo femenino, de los cuales 4 presentan niveles de anticuerpos $>1,000 \mathrm{UI} / \mathrm{ml}, 9$ valores de anticuerpos $>11 \mathrm{UI} / \mathrm{ml}$, y 1 persona obtuvo resultado de anticuerpos negativos $(<9 \mathrm{UI} / \mathrm{ml})$; los 9 casos restantes son del sexo masculino, de estos, 3 presentan valores de anticuerpos $>1,000 \mathrm{UI} / \mathrm{ml}, 5$ presentan niveles $>11 \mathrm{UI} / \mathrm{ml}$, y 1 persona presenta anticuerpos negativos.

Figura 4. Cuantificación de anticuerpos para Hepatitis B según el IMC.

Anticuerpos para Hepatitis B según IMC

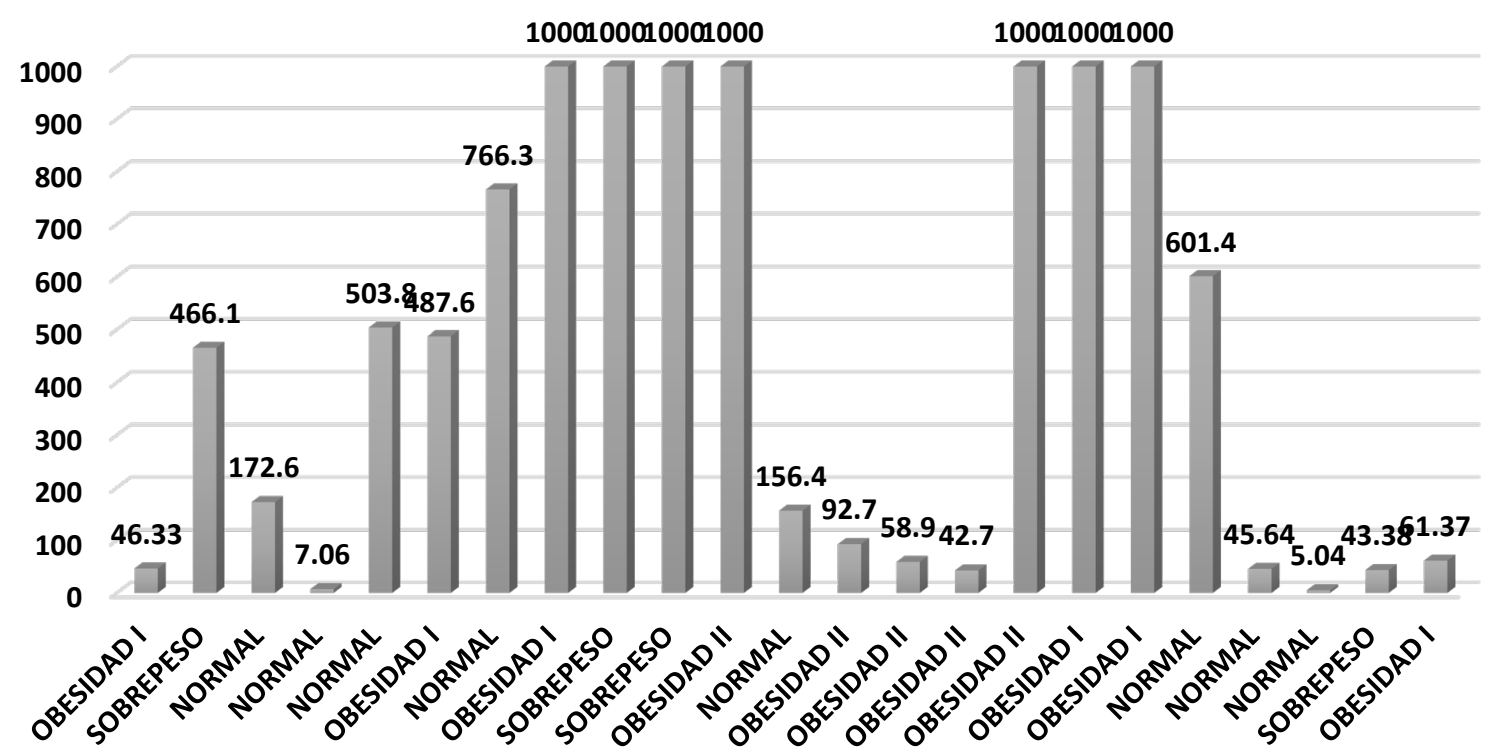

Linares-Portillo (2020). Base de datos del estudio de campo.

De un total de 23 personas incluidas en el estudio, 8 personas poseen un IMC dentro de los rangos normales, y los 15 casos restantes poseen un grado de sobrepeso u obesidad, los valores de anticuerpos obtenidos en cada grupo varían ampliamente. 


\section{Discusión}

Se determinó que de los 23 casos incluidos en el estudio; el 91.30\% mostraron una respuesta inmunológica efectiva contra hepatitis B mientras que el $8.7 \%$ muestra lo contrario y necesita un refuerzo de la vacuna. Aunque los títulos de anti-HBs disminuyen con el tiempo, la duración de la protección que confiere la vacuna es larga; se estima que la protección persiste después de la pauta de vacunación primaria, a pesar de la disminución de los títulos de anticuerpos o incluso ante niveles de anti-HBs indetectables, esto se debe al desarrollo de memoria celular, que permite provocar una respuesta anamnésica.

Se determinó que del $60.87 \%$ de los participantes del estudio pertenecen al género femenino, de las cuales el $17.39 \%$ presentan niveles de anticuerpos $>1,000 \mathrm{UI} / \mathrm{ml}$, el $39.13 \%$ valores de anticuerpos $>11$ $\mathrm{UI} / \mathrm{ml}$, y $4.35 \%$ obtuvo resultado de anticuerpos negativos $(<9 \mathrm{UI} / \mathrm{ml})$; a diferencia del $39.13 \%$ correspondiente al género masculino, el $13.04 \%$ presentan valores de anticuerpos $>1,000 \mathrm{UI} / \mathrm{ml}$, el $21.74 \%$ presentan niveles $>11 \mathrm{UI} / \mathrm{ml}$, y el $4.35 \%$ presenta anticuerpos negativos $(<9 \mathrm{UI} / \mathrm{ml})$, sin embargo no se encuentra una diferencia significativa en cuanto a la diferencia de género, de acuerdo al estudio anteriormente realizado.

Respecto al IMC, se determinó que de las personas con IMC normal, el 25\% (2 casos) no obtuvo niveles significativos de anticuerpos $(<9 \mathrm{Ul} / \mathrm{ml})$, mientras que los que se encontraban en sobrepeso u obesidad todos alcanzaron niveles significativos de anticuerpos, por lo que no se establece una relación significativa con dicho factor. Lo anterior difiere con lo expuesto en la literatura y lo encontrado en un estudio realizado en Colombia, donde respecto al IMC, quienes tienen un valor $>30 \mathrm{~kg} / \mathrm{m} 2$ no seroconvirtieron. (Mera, 2013).

De acuerdo a lo expuesto anteriormente, se evidencia que los resultados que se obtuvieron en el presente estudio no coinciden del todo con lo plasmado en la literatura, así como en los estudios realizados por diversos autores.

\section{Agradecimientos}

A laboratorio Betesda, Hospital modular de Chiquimula, médicos y estudiantes de medicina participantes del estudio.

\section{Referencias}

García, N. (2016). Índice de vacunación efectiva contra hepatitis b, en estudiantes y médicos del departamento de cirugía, abril de 2016 (Tesis de maestría), Guatemala, Universidad de San Carlos, Facultad de ciencias médicas. Recuperado en: http://biblioteca.usac.edu.gt/tesis/05/05_10085.pdf

García, I. y Ory F. (2017). Diagnóstico rápido en serología, abril 2017. Madrid, España, servicio de Microbiología, Hospital Universitario de Getafe. https://doi.org/10.1016/j.eimc.2016.12.013

Hepatitis B Foundation (2019). Análisis de sangre para detectar la hepatitis B, marzo 2019. https://www. hepb.org/languages/spanish/bloodtests/ 


\section{Sobre la autora}

\section{Karina Lissett Linares Portillo}

Médica y Cirujana egresada de la Universidad de San Carlos de Guatemala (USAC) en el año 1997. Realizó la maestría de pediatría en el Hospital General San Juan de Dios (1998-2000). Ha realizado las siguientes investigaciones: Factores de riesgo ambientales en infecciones nosocomiales (1997) y Cuantificación de anticuerpos de superficie contra hepatitis B en estudiantes de medicina y médicos del Hospital Modular de Chiquimula con esquema de vacunación incompleto y vacunados hace 3 años o más (2019). Revisora de la 14 edición en español de farmacología básica y clínica; Bertram G. Katzung. Catedrática titular de Farmacología en Centro Universitario de Oriente, (CUNORI) desde 2009 a la fecha.

Copyright (c) Karina Lissett Linares Portillo, Andrea Espinoza, Linda Sagastume, Kevin Sandoval, María Espina y Sofía Paz

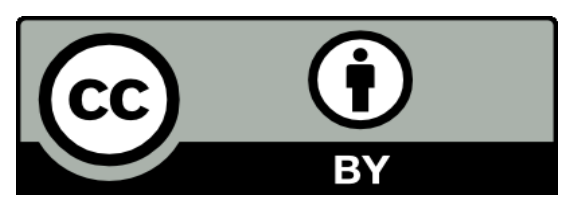

Este texto está protegido por una licencia CreativeCommons 4.0.

Usted es libre para compartir, copiar y redistribuir el material en cualquier medio o formato y adaptar el documento, remezclar, transformar y crear a partir del material para cualquier propósito, incluso comercialmente, siempre que cumpla la condición de atribución: usted debe reconocer el crédito de una obra de manera adecuada, proporcionar un enlace a la licencia, e indicar si se han realizado cambios. Puede hacerlo en cualquier forma razonable, pero no de forma tal que sugiera que tiene el apoyo del licenciante o lo recibe por el uso que hace. 